\section{A institucionalização médica do parto no Brasil}

\author{
The medical institutionalization \\ of childbirth in Brazil
}

Elizabeth Eriko Ishida N agahama 1

Silvia M aria Santiago 2

\footnotetext{
1 Hospital Universitário de M aringá, Universidade Estadual de M aringá. Av. M andacaru 1.590, Parque das Laranjeiras, 87083-170, M aringá PR. eriko@fcm.unicamp.br 2 Departamento de M edicina Preventiva e Social, Faculdade de Ciências M édicas, Universidade Estadual de Campinas.
}

A bstract The object of this study was to point the concept of the establishment of attention in health, especially to the woman's health as a tool of the hegemonic power on attention, specifically in the institutional assistance to the delivery. This work describes the strategies of the institutional hegemony implementation on the female body employed through the Politics in health and practices in medical attention. The power of the State in the establishment of attention is recorded during the historical reconstruction of the maternal and infant health programs of the twenties and eighties, where it was identified that the ideological control of women's health represented ways of control of their sexuality as a reproduction tool. At the practices in medical attention it was discussed questions about the hegemony of the medical power and the female body medication. The delivery hospitalizing process was fundamental to knowledge acquisition in this area and to the development of the medical knowledge, and indeed culminated with the establishment of the medication of the female body.

Key words Delivery, Institutionalization, M edical practices
Resumo Trata-se de abordar o concei to de institucionalização da atenção à saúde, em especial da Saúde da Mulher, como forma de poder hegemônico na atenção, especificamente na assistência institucional ao parto. 0 trabalho descreve as estratégias de implantação da hegemonia institucional sobre o corpo feminino, exercidas através das políticas de saúde e das práticas de atenção médica. 0 poder do Estado na institucionalização da atenção é regi strado no decurso da reconstrução histórica dos programas de saúde materno infantil das décadas de 1920 a 1980, na qual se identificou que o controle ideológico sobrea saúde das mulheres traduziu-se em formas de controle da sua sexualidade como veículo da reprodução. $\mathrm{N}$ as práticas de atenção médica, abordam-se as questões da hegemonia do poder médico e a medicalização do corpo feminino. 0 processo de hospitalização do parto foi fundamental para a apropriação do saber nesta área e para o desenvolvimento do saber médico, culminando com o estabelecimento da medicalização do corpo feminino. Palavras-chave Parto, Instituição, Prática médica 


\section{Introdução}

Instituições encerram um conjunto articulado de saberes (ideologias) e práticas (formas de intervenção normatizadora na vida dos diferentes grupos e classes sociais). Estes conjuntos permeiam grande parte das atividades humanas dentro da sociedade, em cada bloco histórico e objetivam a manutenção da hegemonia (Luz, 1981). Segundo esta concepção, as instituições podem ser compreendidas como a cristalização de modos de poder. A autora estabelece que as táticas para implantação dos saberes de grupos hegemônicos através das instituições podem ser exercidas através das políticas de saúde (discurso institucional), saber médico (ensino e pesquisa) e nas práticas de atenção médica (formas de atuação médica).

Foucault (1982) analisa a natureza política da medicina na sociedade capitalista como uma estratégia de controle social que começa com o controle do corpo. 0 autor questiona se o controle da sexualidade e reprodução não teriam implicações sociais para assegurar o controle populacional, reproduzir a força de trabaIho e os modos que as relações sociais são estabelecidas, de forma a garantir que se tenha uma sexualidade socialmente útil e politicamente conservadora. N este sentido, concorda-se com Vieira (1999), que compreende a medical ização do corpo feminino como um dispositivo social que relaciona questões políticas aos cuidados individuais do corpo da mulher, normalizando, regulando e administrando os aspectos da vida relacionados à reprodução humana.

Este trabalho descreve as estratégias de implantação da hegemonia institucional sobre o corpo feminino, exercidas através das políticas de saúde e das práticas de atenção médica.

\section{Políticas de saúde - a institucionalização da atenção materno-infantil}

\author{
Como institucionalizar algo que pertence \\ à vida afetiva, emocional e sexual? \\ Como institucionalizar como doença \\ um ato fisiológico e natural? \\ (Carneiro, 2000)
}

A proteção da saúde materno-infantil tornouse alvo de políticas governamentais que foram consolidadas nos programas de governo na dé cada de 1920 com a reforma sanitária de Carlos Chagas, seguida de numerosas modificações em nível ministerial e, conseqüentemente, no planejamento e na organização da assistência materno-infantil (Tyrrell \& Carvalho, 1995).

As autoras explicitam que o papel do Estado limitou-se a definir programas de caráter vertical com várias denominações, que mudavam conforme as políticas nacionais e as propostas programáticas e que, desta forma, os aspectos de saúde materno-infantil apresentaram-se abordados somente na dimensão biológica, funcionalista e delimitada essencialmente por cuidados médicos.

0 primeiro órgão governamental voltado exclusivamente para o cuidado da saúde materno-infantil foi o Departamento $\mathrm{N}$ acional da Criança (DNCR), criado em 1940. Suas diretrizes de trabalho visavam integrar os planos e as atividades de proteção à maternidade, à infância e à adolescência, públicos e privados, com os programas de saúde pública em geral. 0 DNCR associou seu projeto educativo à puericultura, enfatizando não só os cuidados com as crianças, mas também com as mães, no que se referia à gravidez e amamentação (Brasil, 1940). Nesse período de atuação do DNCR (1940-1965) existiram duas visões quanto ao significado da atenção prestada ao grupo materno-infantil: uma seria a de quea reprodução se constituía em uma função essencialmente social, interessando muito mais à sociedade que ao indivíduo; a outra era a que encarava as práticas de higiene simplesmente como defesa e conservação da vida. Não se preocupava em disciplinar a reprodução, mas o combate à mortalidade infantil era enfatizado como garantia de se construir uma nação forte, sadia e progressista (Tyrrell \& Carvalho, 1995).

Em 1953 foi criado o M inistério da Saúde, que coordenou, em nível nacional, a assistência materno-infantil. Suas diretrizes iniciais primaram também pelo cunho nacionalista, sendo "um dever imperioso defender de maneira eficaz a criança brasileira, em verdade, ainda o melhor elemento a salvaguardar o futuro da nacionalidade"(Canesqui, 1987).

Portanto, a proteção à maternidade e à infância, como assunto de saúde pública, obedeceu à tendência geral das políticas dessa área a partir do Estado Novo: ela esteve inserida no model o centralizador, concentrado nas ações de puericultura, e voltada para as camadas urbanas mais pobres, com o intuito fundamental de garantir braços fortes para a nação. No final dos anos 50 e início da década de 1960, essa proteção foi perdendo importância para a prio- 
ridade que passou a ser dada ao combate às moléstias endêmicas rurais e, em 1969, o DNCR foi extinto.

Entre 1964 e 1973 instituiu-se um modelo de atenção à saúde médico assistencial privatista, reflexo da intervenção estatal na expansão da medicina previdenciária fundada no cuidado médico individualizado, de base hospitalar e ambulatorial.

A primeira menção a cuidados específicos com o grupo materno-infantil pós-64 apareceu em 1971 no documento Diretrizes Gerais da Política Nacional de Saúde Materno-Infantil (Brasil, 1971). Este documento previa programas de assistência ao parto, ao puerpério, à gravidez de alto risco, ao controle das crianças de 0 a 4 anos de idade, estímulo ao aleitamento materno e nutrição. Considerava ainda a possibilidade de oferecer às mulheres orientação no período intergestacional, com o propósito de espaçar o nascimento dos filhos por problemas de saúde.

A Saúde M aterno-Infantil e o Bem-estar da Família como área programática tem suas raízes na recomendação do Plano Decenal de Saúde para as Américas, produto da III Reunião Especial de M inistros de Saúde das Américas (REM S) realizado em Santiago, Chile, de 2 a 9 de outubro de 1972 (O pas, 1973).

Dessa forma, a saúde materno-infantil e o bem-estar da família, as questões de fertilidade e esterilidade da mulher como área programática ficaram inseridas no movimento em prol da saúde na América Latina, através de políticas internacionais e medidas que visavam à cobertura universal, eficiência operativa, acessibilidade geográfica, institucional e financeira. $E$, torna-se público e amplamente divulgado, 0 conceito universal de saúde, conforme pauta e debates da III REM S. O Brasil, como país membro da O pas/OM S, não poderia fugir às propostas, recomendações e compromissos firmados na referida III REMS.

No contexto da criação do Ministério de Previdência e Assistência Social (M PAS), em 1974, o Programa de Assistência M aterno-Infantil teve como ênfase os programas de prevenção à gravidez de alto risco e suplementação alimentar às gestantes e puérperas de baixa renda. N este documento consta que o grupo materno-infantil é vulnerável por suas características biológicas e sociais, exigindo adequada atenção às suas necessidades através de programas desenvolvidos de maneira sistemática, integral e coordenada (Brasil, 1974). A partir desta versão preliminar em 1974, surge o primeiro programa de atenção ao grupo materno-infantil em 1975: Programa de Saúde M aterno-Infantil (PSM I). Este programa retomava a ênfase com a nutrição do grupo infantil; em relação às mulheres, o alvo eram as gestantes, parturientes, puérperas, e as que estavam em idade fértil. As ações planejadas tinham como objetivo contribuir para a maior produtividade com o ingresso de novas e mais hígidas gerações na força de trabal ho (Brasil, 1975).

Ambos os programas referidos acima previam atividades de planejamento familiar como uma medida para compatibilizar as gestações com as condições do organismo materno, com a garantia do nascimento de crianças saudáveis e da integralização do núcleo familiar.

Com a preocupação de prevenir as gestações de risco, o M inistério da Saúde criou em 1978 o Programa de Prevenção da Gravidez de Alto Risco (PPGAR). 0 propósito de sua elaboração foi regulamentar e operacionalizar as ações de assistência especial e especializada aos riscos reprodutivo e obstétrico, à prevenção de gestações futuras, quando indicada, e ao diagnóstico e tratamento da esterilidade ou da infertilidade (Brasil, 1978).

Em 1980 surgiu o Programa de Ações Básicas de Saúde (Prevsaúde), que pretendia estender a cobertura de cuidados primários de saúde à quase total idade da população brasileira, com articulação simultânea das diversas organizações estatais e privadas em uma rede úni$c a$, hierarquizada e regionalizada. Previa o estabelecimento de um amplo programa maternoinfantil: ações referentes aos intervalos entre os nascimentos dos filhos, informação sel etiva e ampla sobre os diferentes métodos anticoncepcionais e uma revisão da legislação sobre a fecundidade (Canesqui, 1987).

Entretanto, novamente, esta proposta não foi efetivada devido à crise econômica que se agravava e pelas pressões de grupos de interesses relacionados às ligações burocráticas entre os dirigentes dos programas de assistência médico-previdenciária e os empresários do setor da assistência médica.

No final da década de 1970 e início dos anos 80 , alguns profissionais médicos envolvidos na experiência de um Ambulatório de Tocoginecologia Preventiva na U niversidade Estadual de Campinas (U nicamp), discutiam sobre que tipo de atenção seria a melhor e mais adequada para a clientela que procurava os serviços oferecidos pela U nicamp nessa área. Aos 
poucos, foi se tornando claro que a preocupação era "oferecer à mulher uma assistência integral, no sentido de enfatizar a necessidade de o médico se preocupar com o corpo dela como um todo, e não apenas como órgãos isolados a serem tratados por diferentes especialistas" (Osis, 1994).

Paralelamente, os movimentos organizados de mulheres ganhavam destaque nas esferas do poder público. N os primeiros anos da década de 1980 esses movimentos passaram a colocar a questão da sexualidade feminina em outros termos, deslocando o eixo da discussão para situar a anticoncepção no contexto da saúde reprodutiva, como um direito das mulheres. Nesta nova perspectiva, qual quer atividade voltada para a regulação da fecundidade deveria fazer parte de uma abordagem integral da saúde da mulher, mais amplamente ainda, de uma abordagem sobre os direitos das mulheres. Esta mudança do enfoque em relação à regulação da fecundidade foi um fenômeno mundial: especialmente os Estados U nidos mostraram-se muito preocupados com a questão do crescimento populacional do Terceiro M undo, e passaram a enfatizar a necessidade de se controlar a natalidade. A partir desta premissa, fazia-se a recomendação de que os governos possibilitassem a liberdade das pessoas decidirem sobre 0 número de filhos que teriam, oferecendo-Ihes informações eacesso a métodos anticoncepcionais eficazes, vantagens da família pequena e, especialmente, derrubando as barreiras legais às atividades de controle da fecundidade.

Desta forma, na década de 1970, houve interesse de grupos organizados de mulheres em conhecer este modelo de atenção desenvolvido na Unicamp, denominado de Atenção I ntegral à Saúde da Mulher (AISM), bem como em transformá-lo em um programa nacional. Os movimentos de mulheres insistiram que a transformação do conceito de AISM em programa de saúde incluísse um componente de educação sexual e em saúde. Portanto, em 1983, um grupo que reuniu sanitaristas, psicólogas e sociólogas, representantes dos grupos de mulheres, demógrafos e pesquisadores das universidades elaborou o Programa de Assistência Integral à Saúde da M ulher (PAISM ).

Em 1984, o M inistério da Saúde estabeleceu base de ação programática para a Assistência Integral à Saúde da M ulher, com objetivo de incluir a assistência à mulher desde a adolescência até a terceira idade e explicitar o compromisso com o direito das mulheres, na opção de exercer ou não a maternidade e/ou a reprodução, tentando contemplar a mulher em todo o ciclo vital. Neste documento, denominado de Assistência Integral à Saúde da Mulher: Bases de Ação Programática (AISM), publicado pelo M inistério da Saúde em 1984, o conceito de AISM era definido como sendo ações de saúde dirigidas para 0 atendimento global das necessidades prioritárias desse grupo populacional e de aplicação ampla no sistema básico de assistência à saúde. A inclusão de atividades de planejamento familiar no Programa baseava-se nos princípios de eqüidade - oportunidade de acesso às informações e aos meios para a regulação da fertilidade por parte da população - e no controle do risco gravídico, exercido pelo médico (Brasil, 1984).

Ressalta-se, assim, o surgimento do PAISM em meio a três forças: as pressões internacionais para que os países em desenvolvimento controlassem o crescimento populacional; as pressões internas dos movimentos sociais por mudanças na política de saúde; e as pressões dos movimentos de mulheres no sentido de que elas fossem tratadas como cidadãs, na plenitude de seus direitos, o que incluía a atenção à sua saúde como um todo, enão apenas como mães em potencial.

A partir da década de 1980 ocorreu um movimento mundial em prol da humanização do parto e nascimento, uma preocupação crescente em dar lugar a novos paradigmas que considerassem e valorizassem o ser humano em sua totalidade, eque estimulassem os profissionais de saúde a repensarem sua prática, buscando a transformação da realidade no cotidiano do cuidado. A avaliação científica das práticas de assistência evidenciou a efetividade e a segurança de uma atenção ao parto com um mínimo de intervenção sobre a fisiologia, e de muitos procedimentos centrados nas necessidades das parturientes - ao invés de organizados em função das necessidades das instituições. Isto resultou em um novo paradigma de assistência ao parto, denominado de humanista (DavisFloyd, 2001).

Sendo assim, a partir de 1988, o M inistério da Saúde implantou um conjunto de ações por meio de portarias ministeriais que, em seu conjunto, constituiu o Programa de Humanização no Pré natal e Nascimento (PH PN). As características principais do programa são a integralidade da assistência obstétrica e a afirmação dos direitos da mulher incorporados como diretrizes institucionais, com objetivo principal 
de reorganizar a assistência e vincular formalmente o pré-natal ao parto e puerpério, ampliar 0 acesso das mulheres aos serviços de saúde e garantir a qualidade da assistência com a realização de um conjunto mínimo de procedimentos (Brasil, 2000).

Estas medidas têm despertado polêmicas e mobilizado defensores e opositores nos diversos segmentos envolvidos, dentro e fora das instituições de assistência ao parto no Brasil.

\section{Práticas de atenção médica: hegemonia do poder, medicalização do corpo feminino}

\author{
A medicina trata a gravidez ea menopausa \\ como doença, transforma a menstruação \\ em distúrbio crônico e o parto em um evento \\ cirúrgico \\ (Ehrenreich \& English, 1973)
}

A maneira específica pela qual o corpo feminino vem sendo tratado pela medicina a partir do momento em que o transforma em seu objeto de saber e prática traz à tona o tema da medical ização. Segundo M iles (1991) medicalizar significa o processo de transformar aspectos da vida cotidiana em objetos da medicina, de forma a assegurar conformidade às normas sociais.

Esta distorção na prática médica brasileira é determinada por múltiplos fatores - históricos, estruturais, conjunturais -, mas a gênese dessa permissividade é atribuída à forma como a sociedade em geral, e a medicina, em particular, encaram a mulher (Brasil, 2000). N ovamente, reporta-se à expressão de Foucault (1982): uma das formas institucionais mais importantes de controle das classes pelo poder dominante faz-se através da manipulação dos corpos.

Vieira (1999) descreve que o processo de medicalização do corpo feminino teve início 300 anos antes da institucional ização do parto como evento hospitalar e do estabel ecimento da obstetrícia como disciplina médica.

Por um longo período, partejar foi uma tradição exclusiva de mulheres, exercida somente pelas curandeiras, parteiras ou comadres - muIheres de confiança da gestante ou de experiência reconhecida pela comunidade -, pois, em sua dedicação à atividade como um sacerdócio, eram familiarizadas com as manobras externas para facilitar o parto, conheciam a gravidez e 0 puerpério por experiência própria e eram en- carregadas de confortar a parturiente com alimentos, bebidas e palavras agradáveis. Sendo assim, as mulheres preferiam a companhia das parteiras por razões psicológicas, humanitárias e devido ao tabu de mostrar os genitais. Neste período, 0 atendimento ao nascimento era considerado atividade desvalorizada e, portanto, poderia ser deixado aos cuidados femininos pois não estava à altura do cirurgião - o homem da arte. Além disso, os médicos eram raros e pouco familiarizados em assistir o parto e nascimento (Arruda, 1989).

Contudo, no final do século 16, a profissão de parteira sofreu declínio, a partir da utilização do fórcipe obstétrico pelo cirurgião inglês Peter Chamberlain. Segundo Osava \& M ademe (1995), o uso do fórcipe obstétrico influenciou a aceitação da obstetrícia como uma disciplina técnica, científica e dominada pelo homem, pois instaurou o conceito de que é possível comandar o nascimento e que o parto era perigoso, sendo imprescindível a presença de um médico. Pelo fato de as parteiras não terem condições econômicas de adquirir o fórcipe, de serem incapazes de dominar novas técnicas por serem consideradas intelectualmente inferiores aos homens, aliado ao fato de não serem condizentes com o paradigma intervencionista médico, passaram a rejeitá-lo. Desta forma, 0 uso do fórcipe permitiu a intervenção masculina e a substituição do paradigma não intervencionista pela idéia do parto como um ato controlado pelo homem. Além disso, a regulamentação da prática exigiu que as parteiras chamassem cirurgiões para assisti-las, como parte da estratégia do Estado e da I greja para monopolizar o saber acerca da cura das doenças e, assim, legitimá-lo por meio das U niversidades criadas no Renascimento.

Segundo Arruda (1989), as modificações definitivas na assistência ao parto ocorreram a partir do século 17 quando se descobriu o mecanismo da ovulação, pois o entendimento de que a mulher possuía uma estrutura mais delicada do que a do homem levou à percepção do parto como perigoso para a saúde e que a medicina deveria protegêla. 0 modelo cartesiano do dualismo mente/corpo evoluiu para o corpo como uma máquina, sendo o corpo masculino considerado o protótipo desta máquina e o feminino um desvio do padrão masculino, considerado hereditariamente anormal, defeituoso, perigosamente imprevisível, regido pela natureza e carente do controle constante por parte dos homens. Com o advento do capitalismo indus- 
trial, a prática da assistência ao parto se consolidou como exercício monopolizado dos médicos e, assim, foi legitimado e reconhecido.

Este domínio de classe nas formações sociais capitalistas traz à tona o conceito de hegemonia de Gramsci (Gruppi, 1978). 0 conceito refere-se ao poder, à capacidade de direção, de conquistar alianças em toda sua amplitude, que opera não apenas sobre a estrutura econômica e sobre a organização política da sociedade, mas também sobre o modo de pensar, sobre as orientações ideológicas e inclusi ve sobre o modo de conhecer. Neste sentido, o discurso médico da metade do século 19 relativo à obstetrícia caracterizou-se pela defesa da hospital ização do parto e da criação de maternidades. 0 parto deixou de ser privado, íntimo efeminino, e passou a ser vivido de maneira pública, com a presença e interferência de outros atores sociais.

Das regras que fundamentam as relações institucionais, os conceitos básicos para compreensão da organização das instituições como núcleos de poder são três: a hierarquia - marca da subordinação - , a ordem - que garante a estrutura - , e a disci plina - que assegura as relações sociais (Luz, 1981).

A autora aborda em seu trabalho o conceito de Goffman das denominadas "instituições totais" - o hospital e o quartel -, nas quais a disciplina é sua regra mais importante. Nas instituições diretamente ligadas ao Estado, o poder é mediado por um saber soberano, um conjunto de técnicas, de normas de conduta, de proceder e de conhecer. Portanto, através de um processo de formação ideológica, o conjunto de práticas institucionais médicas como um todo medicaliza e institucionaliza o paciente. Sendo assim, o hospital pode ser visto como parte estratégica do exercício da dominação.

Apesar da hospitalização ter sido, em grande parte, responsável pela queda da mortalidade materna e neonatal, o cenário de nascimento transformou-se rapidamente: simbolicamente, a mulher foi despida de sua individualidade, autonomia e sexualidade, por meio do cerimonial de internação - separação da família, remoção de roupas e de objetos pessoais, ritual de limpeza com enema, jejum, não deambular. Ou seja, a atenção foi organizada como uma linha de produção e a mulher transformou-se em propriedade institucional.

Segundo Tanaka (1995), o parto no Brasil foi institucionalizado progressivamente após a Segunda Guerra M undial, período no qual normas e rotinas passaram a ser ditadas para o tra- tamento e comportamento da mulher. A incorporação à medicina de novos conhecimentose habilidades nos campos da assepsia, cirurgia, anestesia, hemoterapia e antibioticoterapia diminuíram, de forma significativa, os riscos hospitalares e ampliaram as possibilidades de intervenção, resultando no aumento progressivo de operações cesarianas.

Sobre esta questão, O sava \& M ademe (1995) , afirmam que "no passado, o uso excessivo do fórcipe obstétrico impressionava os viajantes estrangeiros; hoje, o que impressiona o mundo todo são as excessivas taxas de operações cesarianas".

\section{Considerações finais}

A reconstrução histórica dos programas de saúde materno-infantil demonstrou que o controle ideológico sobre a saúde das mulheres traduzia-se em formas de controle da sua sexualidade como veículo da reprodução, exercido através do aparato institucional da família e do Estado. A própria denominação dos programas de saúde voltados para as mulheres indicava qual era o enfoque do tratamento: em ge ral eram programas de saúde materno-infantil, com estratégias voltadas exclusivamente a intervir sobre os corpos das mulheres- mães, de maneira a assegurar que os corpos dos filhos fossem adequados às necessidades da reprodução social. Portanto, a reconstrução histórica reafirmou o conceito de Luz (1981): as instituições ligadas à saúde se constituem em apareIhos do Estado e todas reproduzem regras do poder dominante na sociedade.

0 cuidado prestado à mulher e à família sofreu modificações significativas principalmente a partir do século 20, com a institucional ização da assistência, passando a predominar o parto hospitalar. 0 processo de hospitalização do parto foi fundamental para a apropriação do saber nesta área e para o desenvolvimento do saber médico, culminando com o estabelecimento da medicalização do corpo feminino. 0 preço da melhoria das condições do parto foi a sua desumanização e a transformação do papel da mulher de sujeito para objeto no processo do parto e nascimento. D esta forma, a apropriação do saber médico e as práticas médicas constituíram fatores determinantes para a institucionalização do parto e a transformação da mulher em propriedade institucional no processo do parto e nascimento. 


\section{Colaboradoras}

EEI N agahama é a autora e a responsável pela elaboração do artigo; eSM Santiago, co-autora, éa responsável pela orientação e revisão do artigo.

\section{Referências bibliográficas}

Arruda A 1989. U m atendimento ao parto para fazer ser e nascer, pp. 35-42. In Quando a paciente é mulher. Relatório do Encontro Nacional da Campanha saúde da Mulher: um direito a ser conquistado. Ministério da Saúde: Brasília.

Brasil M inistério da Saúde 1940. Atos do Poder Executivo. Decreto-lei no 2.024 de 17/02/40. Fixa as bases da organização da proteção à maternidade, à infância eà adolescência em todo o país.

Brasil M inistério da Saúde 1971. Diretrizes gerais da política nacional de saúde materno-infantil. Brasília.

Brasil M inistério da Saúde 1974. Secretaria de Assistência M édica. Coordenação de Proteção M aterno-Infantil. Programas de Saúde M aterno-Infantil. Rio de Janeiro.

Brasil M inistério da Saúde 1975. Secretaria de Assistência M édica. Coordenação de Proteção M aterno-Infantil. Programa de Saúde M aterno-Infantil - bases programáticas. Rio de Janeiro.

Brasil M inistério da Saúde 1978. Secretaria N acional de Programas Especiais de Saúde. Programa de Prevenção da Gravidez de Alto-Risco. Normas para a identificação e controle dos riscos reprodutivos, obstétrico e da infertilidade no Programa de Saúde M aterno-Infantil. Brasilia.

Brasil M inistério da Saúde 1984. Assistência integral à saúde da mulher: bases de ação programática. Centro de Documentação do M inistério da Saúde, Braślia.

Brasil M inistério da Saúde 2000. Programa de humanização no prénatal enascimento: informações para gestores e técnicos. Secretaria de Políticas de Saúde, Área Técnica da Saúde da M ulher, Brasília.

Carneiro LM 2000. Humanizar é preciso. Jornal da Redesaúde 20(5):16-17.

Canesqui AM 1987. Assistência médica e a saúde e reprodução humana. Textos NEPO 13. Campinas.
Davis-Floyd R 2001. The technocratic, humanistic, and holistic paradigms of childbirth. International Journal of Gynecology \& Obstetrics 75(1):5-23.

Ehrenreich B \& English D 1973. Complaints and disorders: the sexual politics of sickness. Writers and Readers Pub. Coop., Londres.

Foucault M 1982. M icrofísica do poder. 3a ed. Graal, Rio de Janeiro.

Gruppi L 1978. 0 conceito de hegemonia em Gramsci. 2a ed. Graal, Rio de Janeiro.

Luz M D 1981. As instituições médicas no Brasil. 2a ed. Graal, Rio de Janeiro.

M iles A 1991. Women, $\mathrm{H}$ ealth and M edicine. Open University Press, M ilton Keynes, Filadélfia.

Organización Panamericana de la Salud/Organização M undial da Saúde (OPAS/OM S) 1973. Plan Decenal para las Américas. Informe final de la III Reunión especial de M inistros de Salud de las Américas. Chile, 2-9 de outubro de 1972. Doc. O ficial № 118. Enero de 1973.

Osava RH \& M amede MV 1995. A assistência ao parto ontem e hoje: a representação social do parto. Jornal Brasileiro de Ginecologia 105(1/2):3-9.

Osis M JM 1994. Atenção integral à saúde da mulher, o conceito e o programa: história de uma intervenção. Dissertação de mestrado. Universidade Estadual de Campinas, Campinas.

Tanaka AC 1995. M aternidade: dilema entre nascimento e morte. Hucitec, São Paulo.

Tyrrell M AR \& Carvalho V 1995. Programas nacionais de saúde materno-infantil: impacto político-social e inserção da enfermagem. EEAN/UFRJ, Rio de Janeiro.

Vieira EM 1999. A medicalização do corpo feminino, pp. 67-78. In K Giffin \& SH Costa. Questões da saúde reprodutiva. Fiocruz, Rio de Janeiro.

Artigo apresentado em 10/03/05

Aprovado em 20/04/05

Versão final apresentada em 20/04/05 